\title{
Comparison of Two Lipid Extraction Methods Produced by Yeast in Cheese Whey
}

\author{
Rodrigo Fernandes Castanha ${ }^{1,2^{*}}$, Lilia Aparecida Salgado de Morais ${ }^{2}$, Adriano Pinto \\ Mariano $^{3}$ and Regina Teresa Rosim Monteiro ${ }^{4}$ \\ ${ }^{1}$ Universidade de São Paulo; Escola Superior de Agricultura "Luiz de Queiroz"; Av. Pádua Dias, 11; 13418-900; \\ Piracicaba - SP - Brasil. ${ }^{2}$ Embrapa Meio Ambiente; Rodovia SP 340 - Km 127,5; C.P.: 69; 13820-000; Jaguariúna \\ - SP - Brasil. ${ }^{3}$ Departamento de Processos Químicos; Faculdade de Engenharia Química; Universidade Estadual \\ de Campinas; C. P.: 6066; 13083-970; Campinas - SP - Brasil. ${ }^{4}$ Laboratório de Ecologia Aplicada; Centro de \\ Energia Nuclear na Agricultura; Universidade de São Paulo; Av. Centenário, 303 São Dimas; C.P.: 96 ; 13400-970 \\ - Piracicaba - SP - Brasil
}

\begin{abstract}
This work aimed to evaluate nine strains of yeast, previously identified as good producers of lipids in honey medium, for selecting the most suitable strain for the production of lipids in cheese whey medium and compared two well known extraction methods of lipids from the culture medium. The highest yield of total lipids was 1.27 g.L $L^{-1}$ produced by Cryptococcus laurentii 11. A comparison was made between the two culture media: cheese whey and liquid YEPG, and two lipid extraction methods: Bligh and Dyer and Folch et al. for C. laurentii. The experiments were performed with $2^{2}$ full factorial design using two factors and two levels. Lipid content was higher in cheese whey and there was no difference in the extraction methods statistically. The method of Bligh and Dyer was used in preference to Folch et al. as it resulted in larger mean of total lipids.
\end{abstract}

Key words: cheese whey, yeast, lipid extraction, microbial oil

\section{INTRODUCTION}

Currently, much attention is being paid to the development of oil-containing microorganisms. Many microorganisms such as micro algae, fungi and bacteria, are capable of accumulating certain oils under special culture conditions. Compared with other vegetable oils, microbial oils have many advantages such as short life cycle, less work required, are less affected by the location, season and climate, and faster growth. With the rapid expansion of biodiesel, microbial oils may become a commodity with the potential for lipid production for biodiesel in the future, although various works associated with oil producing microorganisms still need to be performed ( $\mathrm{Li}$ et al. 2008).

The high cost of biodiesel from oleaginous microorganisms is mainly due to the cost of glucose, which is estimated to be nearly $80 \%$ of the total medium. Thus, considerable efforts have been directed to minimize cost of the carbon source and find alternative sources (Tsigie et al. 2011).

Several co-products and raw materials for food industry and agroindustry have been used to obtain biotechnological products because of their high availability, which represents an alternative source of low commercial value (Silva et al. 2009; Ernandes et al. 2010). Cheese whey is one of the

*Author for correspondence: rodrigo.castanha@embrapa.br 
most abundant by product, which can be employed for the development of various value-added products such as ethanol (Dragone et al. 2011; Koushki et al. 2011), fatty acid methyl esters (Takakuwa and Saito 2010), biopolymer poly (3hydroxybutyrate) (Nickel et al. 2005), biosurfactants (Rodrigues et al. 2006), xanthan gum (Silva et al. 2009), bacteriocins (CladeraOlivera et al. 2004), lactic acid (Ghasemi et al. 2009), citric acid (El-Samragy et al. 1996), gluconic acid (Chaturvedi et al. 1999), $\alpha$-amylase (Ferreyra et al. 1998), $\beta$-galactosidase (Santiago et al. 2004; Manera et al. 2011) and manganese peroxidase (Feijoo et al. 1999).

After increase to $18 \%$ in exports of cheese in 2010, it is estimated that EU exports for 2011 and 2012 would continue to grow, even for the U.S. where cheese production is projected to expand in 2011 to 4.8 million tons, an increase of $3 \%$ to a record 4.9 million tons in 2012. In Brazil, the cheese production reached 648,000 tons in 2010 , and preliminary data indicate an increase to 675,000 tons in 2011 and 700,000 tons projected for 2012 (United States Department of Agriculture - USDA 2011).

An alternative end use for the by-products and industrial waste is the conversion of these substrates to single-cell oil (SCO). Bialy et al. (2011) used frying oil of vegetable residue and meat products for yeast growth and production of fatty acids, Huang et al. (2009) used the hydrolyzate of rice straw for the production of lipids by Trichosporon fermentans, Angerbauer et al. (2008) investigated the potential accumulation of lipids by Lipomyces starkeyi growing in sewage sludge under different conditions, Papanikolaou and Aggelis (2002) studied the growth and production of fatty material by Yarrowia lipolytica in industrial glycerol, Ykema et al. (1988) evaluated the growth and production of single cell oil by Apiotrichum curvatum in whey permeate.

There are two methods originally proposed for the extraction of lipids, viz. Folch et al. (1957) (Papanikolaou et al. 2002; Fakas et al. 2006; Fakas et al. 2008; Fakas et al. 2009) and Bligh and Dyer (1959) (Carvalho 1994; Zhu et al. 2002; Mendes et al. 2006; Duarte 2011; Araujo et al. 2011), which have been used as proposed, or with some modifications. These two methods are cold extraction methods that use the mixture of polar and non-polar solvents for the extraction of fatty acid by removing from the cell membranes, or lipoproteins (Christie 1982; Brum 2004).
This study aimed to evaluate the efficiency of two extraction methods for the production of lipids from yeast grown in the cheese whey medium.

\section{MATERIALS AND METHODS}

\section{Microorganisms and Culture Conditions}

Nine yeast strains isolated from insects and previously identified as good lipids producers in honey medium by Victorelli (2008) were supplied by the Department of Microbiology and Biochemistry of the University Estadual Paulista "Júlio de Mesquita Filho", Campus of Rio Claro, Brazil. They were identified with code as Cryptoccoccus laurentii - 11; Cryptococcus sp. nov.3 - 52; Lipomyces starkey - JAL 425; Lipomyces starkey - JAL 572; Lipomyces starkey JAL 576; Lipomyces starkey - JAL 581; Rhodotorula graminis - CBS 2826; Tricosporon sp. nov.1 - 27b1; Yorrowia lipolytica - 24a. They were grown aerobically at $28 \pm 2^{\circ} \mathrm{C}$ for 72 to $120 \mathrm{~h}$ in YEPG solid medium (yeast extract peptone glucose) containing (g. $\left.\mathrm{L}^{-1}\right) 10$ yeast extract, 20 peptone, 20 glucose and 20 agar, maintained at $4^{\circ} \mathrm{C}$ until inoculation of new culture. The medium was sterilized at $121^{\circ} \mathrm{C}$ for $15 \mathrm{~min}$ prior to use.

\section{Cheese Whey}

Cheese whey was typically supplied in $4 \mathrm{~L}$ volumes by Jamava Laticínios, Santa Cruz da Conceição, Brazil and stored at $4^{\circ} \mathrm{C}$ until used. It was sterilized at $121^{\circ} \mathrm{C}$ for $15 \mathrm{~min}$ in order to coagulate its proteins, centrifuged at $24953.76 \times \mathrm{g}$ and the supernatant was collected and used as culture growth medium. It was sterilized by autoclaving at $121^{\circ} \mathrm{C}$ for $15 \mathrm{~min}$.

\section{Selection of Strain with Improved Efficiency for the Production of Lipids on Cheese Whey}

All the cultures were performed in $125-\mathrm{mL}$ Erlenmeyer's flasks containing $50 \mathrm{~mL}$ of cheese whey medium, inoculated with three plugs of $72 \mathrm{~h}$ culture growth in YEPG medium. Batch experiments for oil production were performed under aerobic conditions on a rotary shaker as described by Xia et al. (2011), (250-mL Erlenmeyer flasks containing $100 \mathrm{~mL}$ of medium); Bialy et al. (2011) $(500 \mathrm{~mL}$ conical flasks containing $200 \mathrm{~mL}$ of medium; Karatay and Dönmez, (2011), (250 mL Erlenmeyer flasks containing $100 \mathrm{~mL}$ growth medium). 
The flasks were incubated at $28^{\circ} \mathrm{C}$ and $180 \mathrm{rpm}$ for $240 \mathrm{~h}$. Total lipid was extracted by the modified method of Bligh and Dyer (1959). Based on the study by Brum et al. (2009), which had demonstrated the method of Bligh and Dyer giving higher yield for oat flaks and chicken breast than Folch et al. method.

\section{Comparison of Culture Media and Extraction Methods for the Production of Lipids by $C$. laurentii - 11}

Experiments were designed to determine the effect of two different methods of lipids extraction: Bligh and Dyer, Folch et al. and two media: cheese whey and YEPG (5 g.L $\mathrm{L}^{-1}$ of yeast extract, 20 g.L $\mathrm{L}^{-1}$ of peptone, 20 g. $\mathrm{L}^{-1}$ of glucose). The experiments were performed with $2^{2}$ full factorial designs with two factors and two levels as shown in Table 1.

Cultures of $C$. laurentti - 11 were performed in 50 $\mathrm{mL}$ of medium, inoculated with three plugs of $72 \mathrm{~h}$ culture growth in YEPG medium. The flasks were incubated at $28^{\circ} \mathrm{C}$ for $240 \mathrm{~h}$ and shaken at 180 rpm.

\section{Dry Biomass}

Cells from a $50 \mathrm{~mL}$ culture growth medium were collected by centrifugation and washed twice with distilled water. Cell dry weight was obtained after drying at $60^{\circ} \mathrm{C}$ to constant weight.

Table 1 - Experimental design for comparison of cultivation medium: Cheese whey (CW) and YEPG and lipid extraction methods: Bligh and Dyer (BD) and Folch et al. (F).

\begin{tabular}{lcc}
\hline Treatments & Extraction methods & Medium \\
\hline BDCW & Bligh and Dyer & Cheese whey \\
BDYEPG & Bligh and Dyer & YEPG \\
FCW & Folch et al. & Cheese whey \\
FYEPG & Folch et al. & YEPG \\
\hline
\end{tabular}

\section{Extraction of Lipids}

Lipid extraction using the modified methodology of Folch et al. (1957) was performed using Chloroform:Methanol (2:1, v/v). Three washes with 20, 10 and $10 \mathrm{~mL}$ of solvent mixture, respectively were carried out for $10 \mathrm{~min}$ each together with ultrasonication for cell membrane disruption. The solvent mixture containing the extracted lipids was separated from the residual biomass by centrifugation and all the fractions from each stage were pooled. This was mixed with $10 \mathrm{~mL}$ of $0.85 \% \mathrm{KCl}$ solution in a separating funnel with stirring vigorously for phase separation. The upper aqueous phase containing water, methanol and non-lipid compounds was discarded and the lower phase (chloroform) was filtered using a filter paper containing $1 \mathrm{~g}$ of anhydrous sodium sulfate. The residue was collected in glass vials. The solvent was removed in the atmosphere of nitrogen.

The modified method of Bligh and Dyer (1959) consisted of a monophasic extraction using Chloroform:Methanol:Water (1:4:0.8, v/v). The dry biomass was first treated with $2 \mathrm{M} \mathrm{HCl}$ to break the cell wall and subsequently centrifuged and the supernatant was discarded. The biomass was then blended with $4.0 \mathrm{~mL}$ water, $10.0 \mathrm{~mL}$ of methanol and $5.0 \mathrm{~mL}$ of chloroform. The mixture was stirred on a rotary shaker for two hours at 220 $\mathrm{rpm}$, then a further dilution was made with $5.0 \mathrm{~mL}$ of chloroform and $5.0 \mathrm{~mL}$ of $1.5 \%$ sodium sulfate. After the separation of the two layers by centrifugation at $173.29 \times \mathrm{x}$ for 2 minutes, the upper aqueous layer containing methanol, water and non-lipid compounds was discarded and the lower chloroform layer was filtered on filter paper containing $1.0 \mathrm{~g}$ of anhydrous sodium sulfate and collected in vials pre-weighed glass. This procedure was repeated for the extraction of lipids remaining in the sample. All the organic phases were pooled and the solvent removed in atmosphere of nitrogen.

Lipids content was expressed as gram lipid per liter of fermentation broth and percentage of gram lipid dry biomass.

\section{Fractionation of Lipids}

The fractionation of the lipids was performed as described by Makri et al. (2010) with modifications. Approximately $100 \mathrm{mg}$ lipids were dissolved in $1.0 \mathrm{~mL}$ chloroform and fractionated by using a column $(15 \mathrm{~mm} \times 100 \mathrm{~mm})$ of $1.0 \mathrm{~g}$ silica gel 60 activated by heating overnight at $100^{\circ} \mathrm{C}$. Successive applications of $100 \mathrm{~mL}$ dichloromethane, $100 \mathrm{~mL}$ acetone, and $50 \mathrm{~mL}$ methanol produced the fractions containing neutral 
lipids (NL), glycolipids plus sphingolipids $(\mathrm{G}+\mathrm{S})$, and phospholipids $(\mathrm{P})$, respectively.

\section{Fatty Acid Composition}

The analysis of fatty acids composition in total lipids and in lipids fractions was performed by Centro de Ciência e Qualidade de Alimentos do Instituto de Tecnologia de Alimentos - ITAL (Campinas, Brazil), according to the methodologies described by Firestone (2009), Food Standards Agency (2002), Hartman and Lago (1973), and Horwitz (2010).

\section{Statistical Analyses}

All the measurements were repeated three times for each treatment. The analysis of variance (ANOVA) was used to analyze the data. The means obtained from each set were compared using the Tukey's test at 0.05 confidence level.

\section{RESULTS AND DISCUSSION}

The highest biomass yield was observed for Lipomyces starkeyi JAL 572 (15.03 g.L $\left.{ }^{-1}\right)$ whose values were statistically similar to the others yeast tested ( $\mathrm{p} \geq 0.05$, by the Tukey test). However the production of total lipids was highly significant $\left(p=4.815 \times 10^{-5}\right)$ by $\mathrm{F}$ test (ANOVA). The strain Cryptococcus laurentii 11 showed the highest production of total lipids $\left(1.27\right.$ g.L $\left.\mathrm{L}^{-1}\right)$ with significant differences compared to other strains using Tukey's test (Table 2).

Table 2 - Production of biomass and lipid content of yeast in cheese whey.

\begin{tabular}{|c|c|c|c|c|c|}
\hline Strain & $\begin{array}{c}\text { Biomass } \\
\text { concentration } \\
\left(\text { g. } \mathrm{L}^{-1}\right)^{*} \\
\end{array}$ & $\begin{array}{c}\text { Total lipid } \\
\text { concentration } \\
\left(\text { g. } \mathrm{L}^{-1}\right)^{*}\end{array}$ & $\begin{array}{c}\text { Biomass } \\
\text { productivity } \\
\left(\text { g. } \mathrm{L}^{-1} \mathbf{h}^{-1} \times \mathbf{1 0}^{-3}\right)\end{array}$ & $\begin{array}{c}\text { Lipids } \\
\text { productivity } \\
\left(\text { g.L } \mathrm{L}^{-1} \mathbf{h}^{-1} \times \mathbf{1 0}^{-3}\right)\end{array}$ & $\begin{array}{c}\text { Lipid } \\
\text { content } \\
(\% \mathrm{w} / \mathrm{w})\end{array}$ \\
\hline Cryptococcus laurentii 11 & $4.57 \pm 0.80^{\mathrm{a}}$ & $1.27 \pm 0.28^{\mathrm{a}}$ & 19.04 & 5.29 & 13.09 \\
\hline Rhodotorula graminis CBS 2826 & $9.71 \pm 1.93^{\mathrm{a}}$ & $0.09 \pm 0.02^{\mathrm{b}}$ & 40.46 & 0.38 & 1.79 \\
\hline Yorrowia lipolytica & $3.76 \pm 0.31^{\mathrm{a}}$ & $0.09 \pm 0.03^{\mathrm{b}}$ & 15.67 & 0.38 & 2.41 \\
\hline Cryptococcus sp. nov3 52 & $4.87 \pm 2.26^{\mathrm{a}}$ & $0.16 \pm 0.12^{b}$ & 20.29 & 0.67 & 3.56 \\
\hline Tricosporon sp. Nov. $127 \mathrm{~b} 1$ & $9.19 \pm 2.83^{\mathrm{a}}$ & $0.13 \pm 0.18^{\mathrm{b}}$ & 38.29 & 0.54 & 1.46 \\
\hline Lipomyces starkeyi JAL 425 & $5.26 \pm 1.62^{\mathrm{a}}$ & $0.12 \pm 0.01^{\mathrm{b}}$ & 21.92 & 0.50 & 2.30 \\
\hline Lipomyces starkeyi JAL 572 & $15.03 \pm 14.39^{\mathrm{a}}$ & $0.12 \pm 0.02^{\mathrm{b}}$ & 62.63 & 0.50 & 0.79 \\
\hline Lipomyces starkeyi JAL 576 & $4.66 \pm 0.46^{\mathrm{a}}$ & $0.13 \pm 0.01^{\mathrm{b}}$ & 19.42 & 0.54 & 2.81 \\
\hline Lipomyces starkeyi JAL 581 & $4.26 \pm 0.07^{\mathrm{a}}$ & $0.14 \pm 0.55^{\mathrm{b}}$ & 17.75 & 0.58 & 3.27 \\
\hline
\end{tabular}

* Data are presented as mean values from triplicate experiments \pm standard deviation

Different letters indicate statistical differences $(p<0.05)$ between samples.

Another important observation was related to the lipids and biomass productivity $\left(\mathrm{g} . \mathrm{L}^{-1} \mathrm{~h}^{-1} \times 10^{-3}\right)$. Despite higher biomass productivity achieved by L. starkeyi JAL 572 (62.63) than by $C$. laurentii 11 (19.04), lipids productivity by $C$. laurentii 11 is substantially higher (5.29) which is easily explained by higher lipid content present in biomass (13.09\%). In fact the best lipid productivity obtained is not so good due to the long fermentation time used $(240 \mathrm{~h})$, however several studies evaluation lipid production at this time or higher than that (Angerbauer et al. 2008; Fakas et al. 2009; Konno et al. 2009; Chatzifragkou et al. 2011). It should be noted that such long fermentation times are common in single cell oil fermentation processes, because prolonged fermentation times are inextricably related to nitrogen limitation and under nitrogen starvation the carbon flux through the metabolic pathways decreases (Wynn et al. 2001; Fakas et al. 2009).

The potential use of agro-industrial residues for oil production were performed by Xue et al. (2006) using sodium glutamate as a carbon source for growth of Rhodotorula glutinis, resulting.Lipids yield 0.2 g. $\mathrm{L}^{-1}$ and lipid content of $9 \%$. Papanikolaou and Aggelis (2002) observed lipid reserves yield of $43 \%$ and above 3.5 g.L $\mathrm{L}^{-1}$ growing Yarrowia lipolytica in industrial glycerol. The accumulation of lipids by Lipomyces starkeyi was evaluated in media containing sewage sludge, which in pre-treatment with ultrasound accumulated values greater than 1 g. $\mathrm{L}^{-1}$ (Angerbauer et al. 2008). When industrial glycerol 
was used as co-substrate, together with stearin the growth of $Y$. lipolytica reached a biomass production of 9 g.L $\mathrm{L}^{-1}$ and $2.8 \mathrm{~g} . \mathrm{L}^{-1}$ of lipids (Papanikolaou et al. 2002).

C. laurentii cultivated in cheese whey presented lipid content greater than $13 \%$ and production of 1.27 g. $\mathrm{L}^{-1}$ under the conditions evaluated. More research work should be carried out with test for optimization of culture conditions in cheese whey providing higher productivity.

Analysis of Variance of experiments performed in full factorial designs (Table 3) showed that the interaction of the extraction methods and medium was not significant $(p=0.143982)$. There was no significant difference in the production of total lipids in the two extraction methods with an average concentration of 0.74 g.L ${ }^{-1}$ and 0.57 g.L ${ }^{-1}$ by Bligh and Dyer and Folch et al. method, respectively.

On the other side variation of media was highly significant ( $p=0,000005)$, by Tukey's test of significance $1 \%$, lipid production in cheese whey medium showed a higher average concentration of 1.12 g.L. ${ }^{-1}$ compared to YEPG medium, which produced in average 0.19 g.L $\mathrm{L}^{-1}$ (Table 4).

Table 3 - ANOVA of Comparison of culture media and extraction methods.

\begin{tabular}{lccccc}
\hline Source of Variation & Degrees of freedom & Sum of squares & Mean squares & Ftest & $\boldsymbol{p}$ value \\
\hline Media & 1 & 2.6133 & 2.6133 & 116.580 & 0.000005 \\
Extraction methods & 1 & 0.0800 & 0.0800 & 3.570 & 0.095497 \\
Media x Extraction methods & 1 & 0.0588 & 0.0588 & 2.623 & 0.143982 \\
Residual & 8 & 0.1793 & 0.0224 & & \\
Total & 11 & 2.9315 & & & \\
\hline
\end{tabular}

Table 4 - Lipid production by $C$. laurentti at different growth media and extraction methods.

\begin{tabular}{ccc}
\hline Treatments & Lipid concentration $\left(\text { g. } \mathbf{L}^{-1}\right)^{*}$ & Lipid content $(\%$ w/w) \\
\hline BDCW & $1.27 \pm 0.28^{\mathrm{a}}$ & 13.09 \\
BDYEPG & $0.20 \pm 0.03^{\mathrm{b}}$ & 2.35 \\
FCW & $0.97 . \pm 0.09^{\mathrm{a}}$ & 5.98 \\
FYEPG & $0.18 \pm 0.05^{\mathrm{b}}$ & 2.04 \\
\hline
\end{tabular}

* Data are presented as mean values from triplicate experiments \pm standard deviation. Different letters indicate statistical differences $(p<0.05)$ between samples. BDCW= method Bligh and Dyer, cheese whey medium; BDYEPG = method Bligh and Dyer, YEPG medium; FCW = method Folch et al., cheese whey medium; FYEPG = method Folch et al., YEPG medium.

Cheese whey composition varies according to the composition of the milk, cheese manufactured and the manufacturing process used (Koushki et al. 2011). The whey contains approximately $7 \%$ solids containing $10-12 \%$ protein, the remainder being.Lactose (74\%), minerals (8\%) and fat (3\%) (Morr 1989).

C. laurentii showed superior final lipid content in cheese whey under the conditions evaluated, indicating the cheese whey as a better medium for growth of $C$. laurentii and production of lipids.

Currently some investigators have compared the extraction methods for microbial lipids. Kanda et al. (2012) evaluated the lipid extraction from microalgae with dimethyl ether and the method of Bligh and Dyer, observed equivalent yield between the two methods. Cescut et al. (2011) compared the pressurized liquid extraction with classical methods of Bligh and Dyer modified and Soxhlet extraction for strain of Rhodotorula glutinis, they found no significant difference in extraction efficiency between the pressurized liquid extraction with the method of Bligh and Dyer modified, although both were higher efficient than Soxhlet apparatus. Burja et al. (2007) studied various methods for extracting fatty acids from Thraustochytrium sp. ONC-T18 and they obtained larger amounts of fatty acids using the method of Bligh and Dyer miniaturized.

Traditionally the binary mixture of chloroform and methanol $(2: 1 \mathrm{v} / \mathrm{v})$ and the use of ternary solvent systems C:M:W have been considered simple and rapid methods for the extraction and purification of lipids from biological materials (Zhu et al. 2002). The oil extraction must be performed by methods that present less impairment of quality of the oil. Study by Brum et al. (2009) showed that the method of Soxhlet with a single apolar solvent (n-hexane) affected the quality of the lipid fraction of oat flake and chicken breast demonstrated by 
the presence of peroxides and by increasing the oleic acid content, indicating the methodology Bligh and Dyer when you have an interest in future use of lipid fractions.

Vicente et al. (2009) compared different total lipid extraction methods from fungal biomass of Mucor circinelloides. Mixtures containing chloroform/methanol and chloroform/methanol/ water $(\mathrm{C}: \mathrm{M}$, and $\mathrm{C}$ : $\mathrm{M}: \mathrm{A})$ obtained the greatest amount of lipid extracted, with similar results (19.9\% and $19 \%$ by dry weight, respectively). In our work, extraction method using three solvents showed no statistical differences compared to the extraction system with two solvents, however had larger mean of total lipids, which was took into account in chosen the method.

The total lipids produced by $C$. laurentii extracted from Bligh and Dyer method are mainly comprised of 16- and 18-carbon-chain fatty acids, predominantly oleic (C18:1), stearic (C18:0), palmitic (C16:0), linoleic (C18:2) and lignoceric (C24:0) acid (Table 5).

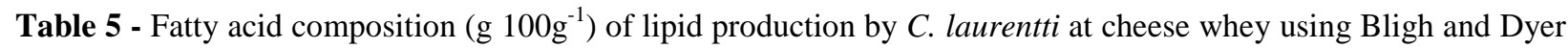
(1959) extraction method.

\begin{tabular}{lc}
\hline Fatty acid & C. laurentii 11 \\
\hline Myristic (C14:0) & 0.44 \\
Pentadecanoic (C15:0) & 0.26 \\
Palmitic (C16:0) & 20.10 \\
Margaritic (C17:0) & 0.56 \\
Stearic (C18:0) & 27.49 \\
Oleic (C18:1) & 34.37 \\
Linoleic (C18:2) & 4.82 \\
Arachydic (C20:0) & 1.15 \\
Behenic (C22:0) & 0.83 \\
Lignoceric (C24:0) & 4.79 \\
\hline
\end{tabular}

The high content $(55.62 \%)$ of saturated fatty acids lipids and the high cetane number related to them, is an indication that the lipids is suitable for the production of a biodiesel with excellent burning characteristics (Mittelbach and Remschmied 2004).

The fractionation of the lipids indicated that neutral lipids were the predominant fraction $(89.1 \%)$ followed by glycolipids plus sphingolipids $(6.9 \%)$ and the phospholipids fraction $(4.0 \%)$, this distribution is especially interesting for biodiesel production because neutral lipids are more readily converted to biodiesel than are polar lipids contained in membranes, thus making it less problematic biodiesel production.

\section{CONCLUSIONS}

There was no significant difference in the comparison of the two methods of extraction of lipids. The strain $C$. laurentii 11 showed higher yields of lipids in cheese whey medium, compared with other eight strains and the whey medium led to more lipid yield than YEPD. The present study showed an alternative way of cheese whey valorization. Future investigations should focus on the optimization of the culture conditions for improvement lipid accumulation yields.

\section{ACKNOWLEDGMENTS}

Jamava Laticínios, Santa Cruz da Conceição, Brazil, is acknowledged for the donation of cheese whey and also Department of Microbiology and Biochemistry of the University Estadual Paulista "Júlio de Mesquita Filho" especially Dr. Dejanira de Franceschi de Angelis for the strains used in this study. R.T.R. Monteiro thanks National Council for Scientific and Technological Development $(\mathrm{CNPq})$ from the researcher grant.

\section{REFERENCES}

Angerbauer C, Siebenhofer M, Mittelbach M, Guebitz, GM. Conversion of sewage sludge into lipids by Lipomyces starkeyi for biodiesel production. Bioresour Technol. 2008; 99: 3051-3056.

Araujo GS, Matos LJBL, Gonçalves LRB, Fernandes FAN, Farias WRL. Bioprospecting for oil producing microalgal strains: Evaluation of oil and biomass production for ten microalgal strains. Bioresour Technol. 2011; 102: 5248-5250. 
Bialy, HE, Gomaa, OM, Azab KS. Conversion of oil waste to valuable fatty acids using oleaginous yeast. World J Microbiol Biotechnol. 2011; 27: 2791-2798.

Bligh EG, Dyer WJ. A rapid method of total lipid extraction and purification. Can J Biochem Physiol. 1959; 37: 911-917.

Brum AAS, Arruda LF, Reginato-d'Arce MAB. Métodos de extração e qualidade da fração lipídica de matérias-primas de origem vegetal e animal. Quim Nova. 2009; 32: 849-854.

Brum AAS. Métodos de extração e qualidade da fração lipídica [Ms Thesis]. Piracicaba, Brazil: Universidade de São Paulo - Escola Superior de Agricultura "Luiz de Queiroz"; 2004.

Burja AM, Armenta RE, Radianingtyas H, Barrow CJ. Evaluation of fatty acid extraction methods for Thraustochytrium sp. ONC-T18 J Agric Food Chem. 2007; 55: 4795-4801.

Carvalho PO. Produção de ácido gama linolênico por nova linhagem de Mucor sp. e estudo das condições de fermentação [Ms Thesis]. Campinas, Brazil: Universidade Estadual de Campinas. Faculdade de Engenharia de Alimentos; 1994.

Cescut J, Severac E, Molina-Jouve C, Uribelarrea JL. Optimizing pressurized liquid extraction of microbial lipids using the response surface method. $J$ Chromatogr. A 2011; 1218: 373-379.

Chaturvedi M, Subramani S, Madamwar D. Fermentative production of gluconic acid using cheese whey. J Food Sci Technol. 1999; 36: 361364.

Chatzifragkou A, Makri A, Belka A, Bellou S, Mavrou M, Mastoridou M, et al. Biotechnological conversions of biodiesel derived waste glycerol by yeast and fungal species. Energy. 2011; 36: 10971108.

Christie WW. Chromatographic and spectroscopic analysis of lipids: general principles. In: Christie WW, editor. Lipid analysis. Oxford: Pergamon Press; 1982. p. 25-49.

Cladera-Olivera F, Caron GR, Brandelli A. Bacteriocin production by Bacillus licheniformis strain $\mathrm{P} 40$ in cheese whey using response surface methodology. Biochem Eng J. 2004; 21: 53-58.

Dragone G, Mussatto SI, Silva JBA, Teixeira JA. Optimal fermentation conditions for maximizing the ethanol production by Kluyveromyces fragilis from cheese whey powder. Biomass Bioenerg. 2011; 35: 1977-1982.

Duarte SH. Utilização de glicerol proveniente da síntese do biodiesel para a produção de lipídeos por leveduras silvestres [Ms Thesis]. Campinas, Brazil: Universidade Estadual de Campinas. Faculdade de Engenharia de Alimentos; 2011.

El-Samragy YA, Khorshid MA, Foda MI, Shehata AE. Effect of fermentation conditions on the production of citric acid from cheese whey by Aspergillus niger. Int J Food Microbiol. 1996; 29: 411-416.
Ernandes FMPG, Boscolo M, Cruz CHG. Influência da composição do meio para a produção de Zimomonas mobilis. Acta Sci Technol. 2010; 32(1): 21-26.

Fakas S, Papanikolaou S, Galiotou-Panayotou M, Komaitis M, Aggelis G. Lipids of Cunninghamella echinulata with emphasis to $\gamma$-linolenic acid distribution among.Lipid classes. Appl Microbiol Biotechnol. 2006; 73: 676-683.

Fakas S, Papanikolaou S, Galiotou-Panayotou M, Komaitis M, Aggelis G. Organic nitrogen of tomato waste hydrolysate enhances glucose uptake and lipid accumulation in Cunninghamella echinulata. J Appl Microbiol. 2008; 05: 1062-1070.

Fakas S, Papanikolaoua S, Batsosa A, GaliotouPanayotoua M, Mallouchosa A, Aggelis G. Evaluating renewable carbon sources as substrates for single cell oil production by Cunninghamella echinulata and Mortierella isabellina. Biomass Bioenerg. 2009; 33: 573-580.

Feijoo G, Moreira MT, Roca E, Lema JM. Use of cheese whey as a substrate to produce manganese peroxidase by Bjerkandera sp BOS55. J Ind Microbiol Biotechnol. 1999; 23: 86-90.

Ferreyra R, Lorda G, Balatti A. Production of $\alpha$-amilase in acid cheese whey culture media with automatic $\mathrm{pH}$ control. Rev Microbiol. 1998; 29: 259-264.

Firestone D. Official methods and recommended practices of the American Oil Chemists' Society. In: Royal Society of Chemistry, The composition of foods, 6th ed. Cambridge: Urbana; 2009. p. 1-66.

Folch J, Lees, M, Stanley GHS. A simple method for the isolation and purification of total lipids from animal tissues. J Biol Chem. 1957; 226: 497-509.

Food Standards Agency. The composition of foods. 6th ed. Cambridge: Royal Society of Chemistry; 2002.

Ghasemi M, Najafpour G, Rahimnejad M, Beigi PA, Sedighi M, Hashemiyeh B. Effect of different media on production of lactic acid from whey by Lactobacillus bulgaricus. Afr J Biotechnol. 2009; 8: 81-84.

Hartman L, Lago RCA. Rapid preparation of fatty acid methyl esters from lipids. Lab Pract. 1973; 22: 475476.

Horwitz W. Official methods of analysis of the Association of Official Analytical Chemists. 18th ed. Gaithersburg: AOAC; 2010.

Huang C, Zong MH, Wu H, Liu QP. Microbial oil production from rice straw hydrolysate by Trichosporon fermentans. Bioresour Technol. 2009; 100: 4535-4538.

Kanda H, Li P, Ikehara T, Yasumoto-Hirose M. Lipids extracted from several species of natural blue-green microalgae by dimethyl ether: Extraction yield and properties. Fuel. 2012; 95: 88-92.

Karatay SE, Dönmez G. Improving the lipid accumulation properties of the yeast cells for biodiesel production using molasses. Bioresour Technol. 2010; 101: 7988-7990. 
Konno A, Susuki Y, Ogawa T, Taniuchi T. UV Irradiation promotes de the accumulation of triglyceride in Lipomyces lipofer. Biosc Biotechnol Biochem. 2009; 73:2474-2477.

Koushki M.R, Jafari M, Azizi M. Comparison of ethanol production from cheese whey permeate by two yeast strains. J Food Sci Technol. [Internet]. 2011. [cited 2012 Mar. 22]. Available from: http://www.springerlink.com/content/u327568j57576 460/fulltext.html

Li Q, Du W, Liu D. Perspectives of microbial oils for biodiesel production. Appl Microbiol Biotechnol. 2008; 80:749-756.

Makri A, Fakas S, Aggelis G.. Metabolic activities of biotechnological interest in Yarrowia lipolytica grown on glycerol in repeated batch cultures. Bioresour Technol. 2010; 101: 2351-2358.

Manera AP, Ores JC, Ribeiro VA, Rodrigues MI, Kalil SJ, Filho FM. Utilização de resíduos agroindustriais em processo biotecnológico para produção de $\beta$ galactosidase de Kluyveromyces marxianus CCT7082. Acta Sci Technol. 2011; 33: 155-161.

Mendes RL, Reis AD, Palavra AF. Supercritical $\mathrm{CO}_{2}$ extraction of c-linolenic acid and other lipids from Arthrospira (Spirulina) maxima: Comparison with organic solvent extraction. Food Chem. 2006; 99: 5763.

Mittelbach M, Remschmied C Biodiesel - The compreensive Handbook (1st ed) Graz: Austria; 2004.

Morr CV. Whey proteins: manufacture. In: Fox PF. (ed.). Developments in dairy chemistry-4: functional milk proteins. New York: Elsevier Applied Science; 1989. p.245-284.

Nikel PI, Pettinari MJ, Méndez BS, Galvagno MA. Statistical optimization of a culture medium for biomass and poly(3-hydroxybutyrate) production by a recombinant Escherichia coli strain using agroindustrial byproducts. Int Microbiol. 2005; 8: 243-250.

Papanikolaou S, Aggelis G. Lipid production by Yarrowia lipolytica growing on industrial glycerol in a single-stage continuous culture. Bioresour Technol. 2002; 82: 43-49.

Papanikolaou S, Chevalot I, Komaitis M, Marc I, Aggelis G. Single cell oil production by Yarrowia lipolytica growing on an industrial derivative of animal fat in batch cultures. Appl Microbiol Biotechnol. 2002; 58: 308-312.

Rodrigues LR, Teixeira JA, Oliveira R. Low-cost fermentative medium for biosurfactant production by probiotic bacteria. Biochem Eng J. 2006; 32: 135142.
Santiago PA, Marquez LDS, Cardoso VL, Ribeiro EJ. Estudo da produção de $\beta$-galactosidase por fermentação de soro de queijo com Kluyveromyces marxianus. Cienc Tecnol Aliment. 2004; 24: 567-572.

Silva GAB, Almeida WES, Cortes MS, Martins ES. Produção e caracterização de protease obtida por Gliocladium verticilloides através da fermentação em estado sólido de subprodutos agroindustriais. Rev Bras Tecnol Agroindustrial. 2009; 3(1): 28-41.

Takakuwa N, Saito K. Conversion of beet molasses and cheese whey into fatty acid methyl esters by the yeast Cryptococcus curvatus. J Oil Sci. 2010; 5: 255-260.

Tsigie YA, Wang CY, Truong CT, Ju YH. Lipid production from Yarrowia lipolytica Po1g grown in sugarcane bagasse hydrolysate. Bioresour Technol. 2011; 102: 9216-9222.

United States Department of Agriculture. Dairy: world markets and trade [Internet] July 2011 [updated July 2011; cited 2012 Jan. 10] Available from: http://www.fas.usda.gov/dairy_arc.asp

VicenteI G, Bautista LF, Rodríguez R, Gutiérrez FJ, Sádaba I, Ruiz-Vázquez RM, et al. Biodiesel production from biomass of an oleaginous fungus. Biochem Eng J. 2009; 48: 22-27.

Victorelli R. Seleção de leveduras produtoras de lipídeos. 2008. 64 p. [Trabalho de Conclusão de Curso de Bacharel em Ciências Biológicas]. Rio Claro, Brazil: Instituto de Biociências, Universidade Estadual Paulista "Júlio de Mesquita Filho"; 2008.

Wynn J, Hamid A, Li Y, Ratledge C. Biochemical events leading to the diversion of carbon into storage lipids in the oleaginous fungi Mucor circinelloides and Mortierella alpina. Microbiol. 2001; 147: 285764.

Xia C, Zhang J, Zhang W, Hu B. A new cultivation method for microbial oil production: cell pelletization and lipid accumulation by Mucor circinelloides. Biotechnol Biofuels. 2011; 4: 15.

Xue FY, Zhang X, Luo H, Tan TW. A new method for preparing raw material for biodiesel production. Process Biochem. 2006; 41: 1699-1702.

Ykema A, Verbree EC, Kater MM, Smit H. Optimization of lipid production in the oleaginous yeast Apiotricum curvatum in wheypermeat. Appl Microbiol Biotechnol. 1988; 29: 211-218.

Zhu M, Zhou PP, Yu LJ. Extraction of lipids from Mortierella alpina and enrichment of arachidonic acid from the fungal lipids. Bioresour Technol. 2002; 84: 93-95.

Received: April 23, 2012; Accepted: May 21, 2013. 